\title{
Lições organizacionais vindas da Antártica
}

\author{
Maria Ester de Freitas \\ Escola de Administração de Empresas de São Paulo
}

\begin{abstract}
Este artigo foi escrito em 2011, com base em relatório de pesquisa apresentado ao FGV/GVPesquisa em 2010; portanto, antes do acidente ocorrido na Estação Antártica Comandante Ferraz, em 25 de fevereiro de 2012. Nosso estudo foca um modelo de gestão pública que se fundamenta na cooperação, representado pelo Programa Antártico Brasileiro (Proantar), em relação ao qual realizamos uma pesquisa empírica exploratória sobre o quotidiano dos pesquisadores que trabalham na Antártica. O objetivo foi entender como as equipes são formadas, como executam seus trabalhos e interagem com os colegas de outras instituições e, também, a maneira como lidam com o isolamento e as condições limitadas de trabalho. Com base nesses resultados, ampliamos o escopo do estudo para uma análise organizacional através de analogias baseadas em metáforas, tomando o continente antártico como uma organização específica. Nossa pergunta-chave é: como uma análise organizacional da Antártica poderá contribuir para a gestão de organizações públicas ou privadas baseadas no conhecimento e na cooperação?
\end{abstract}

Palavras-chave: cooperação multidisciplinar; organizações públicas complexas; trabalho em ambientes extremos; comunidade de conhecimentos; pesquisadores antárticos.

\section{Lessiones organizacionales procedentes de la Antártida}

Este artículo fue escrito en 2011, basándose en el informe de investigación presentado a la FGV/GVPesquisa, así que antes del accidente ocurrido en la estación antártica Comandante Ferraz el 25/2/2012. Nuestro estudio se centra en un modelo de gestión pública basada en la cooperación, representada por el Programa Antártico Brasileño (Proantar), en el que llevamos a cabo una investigación exploratoria empíricos sobre la vida cotidiana de los científicos que trabajan en la Antártica, tratando de comprender cómo se forman los equipos, realizan su trabajo, interactúan con colegas de otras instituciones y hacen frente a las exigencias de aislamiento y las condiciones limitadas de trabajo. Con base en estos resultados ampliamos el alcance del estudio para un análisis de la organización, el uso de metáforas sobre la base de analogías, teniendo el continente antártico como una organización específica. Nuestra pregunta clave es: ¿cómo un análisis organizacional de la Antártica puede contribuir al aprendizaje en la gestión de organizaciones públicas o privadas basadas en el conocimiento y la cooperación?

Palabras clave: cooperación multidisciplinaria; organizaciones públicas complejas; trabajo en ambientes extremos; comunidad de conocimiento; investigadores antárticos.

Artigo recebido em 1o fev. 2012 e aceito em 20 abr. 2012. Agradecemos as valiosas contribuições da doutora Tania Brito, que exerceu a Coordenação Ambiental do Proantar por mais de 20 anos. 


\section{Organizational lessons from Antarctica}

This article was written in 2011, based on the research report presented to FGV/GVPesquisa em 2010, so before the accident at Comandante Ferraz Antarctic Station, on 02.25.2012. Our focus is a managerial model based on cooperation, represented by the Brazilian Antarctic Program (Proantar), on which we conducting an empirical research on the daily life of Brazilian researchers who work in Antarctica, searching to understanding how the teams organize their work, interact to different colleagues, institutions and nationalities, deal with isolating and so limited conditions of work. Based on these findings we expanded the scope of the study to conduct an organizational analysis which takes the Antarctic continent as an organization. Our key-question is: how might an organizational analysis of Antarctic Program contribute to the management of organizations based on knowledge and cooperation?

KEYWORDs: multidisciplinary cooperation; public complex organizations; work in extreme environments; community of knowledge; Antarctic researchers.

\section{Introdução}

O silêncio antártico é rompido em todo verão pela chegada maciça de profissionais, que trabalharão em seus projetos em diferentes tipos de alojamento. A grande maioria se hospeda em estações científicas, as quais dispõem de infraestrutura mais complexa, em particular, relacionada com a instalação de laboratórios e equipamentos para acondicionamento e preservação de amostras dos materiais de pesquisa.

A Estação Antártica Comandante Ferraz (EACF), de bandeira brasileira, acomoda no verão em torno de 60 pessoas, entre pesquisadores civis e militares responsáveis pela segurança e manutenção da estação, grupo-base ligado ao Arsenal da Marinha Brasileira. Neste verão de 2012, a estação estava com sua capacidade lotada, quando foi atingida por um incêndio na madrugada de 25 de fevereiro, que provocou a morte de dois militares integrantes do grupo-base, a destruição de equipamentos e instalações e a perda de amostras e materiais de pesquisa. A comunidade científica mundial se solidarizou com os brasileiros.

Não são incomuns incêndios na Antártica, em virtude do clima muito seco e da necessidade de manutenção de grandes estoques de produtos (alguns inflamáveis) para o trabalho e a conservação das instalações, considerando que o abastecimento é feito apenas uma vez por ano por navios e aviões que servem de apoio à atividade científica. Cabe observar que o cronograma brasileiro é semelhante ao adotado pelas outras estações científicas, pois durante o inverno a população que permanece na Antártica é extremamente reduzida e o trabalho de pesquisa é limitado ao mínimo possível, em virtude das condições extremas de frio, dos ventos e da falta de luz, que inviabilizam transportes na região.

Segundo investigações preliminares, o acidente na EACF começou na casa de máquinas e o fogo destruiu em torno de $70 \%$ das instalações da estação, que é construída em módulos de contêineres, interligados para favorecer a movimentação de pessoas em ambiente com temperatura controlada. Parte da pesquisa antártica brasileira foi perdida e ficará paralisada, podendo ser retomada apenas quando a nova estação for construída. As pesquisas ligadas a 
laboratórios que foram construídos em módulos independentes ou que se realizam nos navios ou em refúgios não sofrerão solução de continuidade. As estações científicas de vários países ofereceram suas instalações para que os pesquisadores brasileiros continuem a realizar as suas pesquisas in loco, entre elas as do Chile, da Argentina e da Polônia.

O Programa Antártico Brasileiro (Proantar) existe há 30 anos e a EACF foi inaugurada em 1984 desenvolvendo um corpo de pesquisas já consolidado e respeitado pela comunidade internacional. Participar da pesquisa na Antártica significa fazer parte de um seleto grupo de nações que podem decidir o destino daquele continente altamente estratégico e encontrar respostas complexas para vários problemas que afetam o planeta. O reconhecimento de um país como membro ativo de uma comunidade científica desse porte tem uma validade que apenas um PIB elevado não pode atribuir. O programa brasileiro envolve cerca de 250 pesquisadores, que trabalham na estação, nos navios e nos refúgios. Eles são ligados a diversas instituições de diferentes regiões do Brasil e apresentam seus projetos para financiamento através dos editais do $\mathrm{CNPq}$ e dos institutos Nacionais de Ciência e Tecnologia, dedicados à pesquisa antártica.

Segundo artigo recententemente publicado na revista da Fapesp (Marques, 2012), o governo brasileiro estima que a nova estação estará em funcionamento em 2016; ou seja, serão necessários quatro anos para implementação do projeto, devendo ser considerado que apenas no verão é possível transportar e construir estruturas naquelas terras. Os pesquisadores antárticos aguardam a oportunidade de se manifestar sobre o modelo a ser adotado na nova arquitetura física e também sobre os novos rumos do programa antártico, em relação ao qual reivindicam maior participação, menos burocracia e mais recursos orçamentários. É consenso entre os pesquisadores que o programa brasileiro carece de planejamento no longo prazo e de maior integração das instituições que dele participam. O acidente abre espaço para um novo debate sobre o futuro do programa, sua estrutura organizacional, novas fontes e formas de financiamento, bem como sobre a expansão da cooperação internacional e a divulgação de seus resultados.

Este artigo nasceu de uma pesquisa feita com pesquisadores brasileiros do programa antártico sobre aspectos organizacionais, cujo relatório foi apresentado em 2010 à FGV/ GVPesquisa. Uma versão preliminar do artigo foi apresentada na área temática "Managing without managers in organizations based on knowledge", do European Group on Organizational Simbolism (Egos), em 2011, na Suécia. Esperamos que esse registro histórico do programa e sua análise possam contribuir para a melhoria do novo Proantar, que surgirá das cinzas do verão de 2012. Nesse sentido, atribuímos a este artigo o valor de uma contribuição técnica na área organizacional e uma modesta homenagem a nossos colegas pesquisadores antárticos, resgatando a memória de seu cotidiano e esclarecendo determinados aspectos que podem ser modificados no futuro.

Também acreditamos que algumas lições podem ser aprendidas por organizações em geral, a partir da análise de um universo tão diferente e tão distante quanto aquele que se desenvolvia no Programa Antártico Brasileiro. Da mesma forma, entendemos que tais lições podem ser proveitosas no âmbito do próprio conjunto dos trabalhos antárticos, levando em conta sua complexidade estrutural, os novos modelos organizacionais derivados da participa- 
ção de múltiplas instituições, a incorporação tecnológica intensiva e a diversidade das equipes profissionais, bem como as condições ambientais extremas em que o trabalho é realizado. Nesse sentido, deve ser ressaltado que organizações complexas baseadas em conhecimento constroem novas formas de organização do trabalho, visando não apenas a uma maior contribuição por parte de suas equipes, mas também complementar expertises, ampliar análises e melhorar a qualidade da resolução de problemas, buscando fomentar a cooperação entre os membros do grupo (Boisot et al., 2011; Théry, 2002).

Assumimos que os pesquisadores na Antártica são regulados por uma filosofia de trabalho baseada na cooperação. Tal filosofia encontra sua essência no Tratado da Antártica, incentivando-os a decifrar o desconhecido, desenvolver em conjunto estudos interdisciplinares, integrar conhecimentos e divulgar os resultados, bem como desenvolver fortes laços subjetivos com o trabalho e entre os membros do grupo (Carrieri et al., 2010; Carrieri e Saraiva, 2007; Enriquez, 1992; Motta e Freitas, 2000; Weick, 1987, 1995). O Proantar é um sistema organizacional multi-institucional público complexo, que define, planeja e executa as atividades brasileiras no continente antártico, envolvendo profissionais e cientistas altamente qualificados, os quais desenvolvem seus projetos sob condições físicas, sociais, geográficas, geológicas, climáticas e psicológicas sem equivalente.

Para conhecer as peculiaridades do trabalho antártico, conduzimos uma pesquisa empírica que nos permitiu apreender as singularidades desse sistema e nos possibilitou ampliar o escopo desse objeto de estudo (Vergara, 2008). Após analisar os resultados da pesquisa, buscamos responder à seguinte questão-chave: como uma análise organizacional da Antártica poderá contribuir para a gestão em organizações baseadas no conhecimento e na cooperação?

Este estudo foi estruturado em cinco partes: 1. Notas sobre o trabalho realizado em lugares extremos; 2. O contexto antártico e a complexidade do Proantar; 3. Pesquisa empírica: trabalhadores antárticos brasileiros; 4. Uma análise organizacional da Antártica; e 5. Conclusões.

\section{Notas sobre o trabalho realizado em lugares extremos}

O trabalho é uma categoria genérica que varia em sua natureza, forma, exigências e locais de execução. O retrato mais comum parece ser o do trabalho administrativo ou industrial, realizado em confortáveis prédios em regiões urbanas. Contudo, existem trabalhos realizados em condições e locais especiais, alguns deles chamados de ambientes extremos, sejam na terra, nos mares ou no céu. Sem a pretensão de esgotar as possibilidades, essa categoria pode ser exemplificada pelos: a) observatórios astronômicos, geralmente situados em locais isolados em elevada altitude; b) as estações científicas situadas em terras polares; c) as plataformas de prospecção e produção de petróleo e gás natural, constituindo verdadeiras cidades no mar; d) os submarinos militares nucleares, com tripulantes confinados por vários meses; e e) a estação internacional espacial, com tripulação permanente para estada de seis meses.

À medida que os conhecimentos científicos e tecnológicos avançam, as organizações expandem os seus limites, assumem novos riscos e realizam novas descobertas (Farjoun e 
Starbuck, 2007; Starbuck e Farjoun, 2005), despertando o crescente interesse de estudiosos para a vida e o trabalho nesses ambientes extremos (Amils et al., 2007; Barnett e Kring, 2003; Bishop, 2004; Palinkas e Browner, 1995; Burgierman, 2003). Esses estudos têm em comum a preocupação com as condições de trabalho e os impactos na saúde dos trabalhadores, os fatores fisiológicos, psicológicos e psicossociais que afetam o desempenho dos grupos, a influência do tamanho do grupo e a satisfação no trabalho durante o processo de adaptação dos grupos.

Alguns estudos referentes à vida e ao trabalho nas estações científicas na Antártica investigam efeitos psicológicos nas equipes que trabalham no verão e/ou no inverno (Palinkas et al., 2004; Palinkas e Suedfeld, 2008), os aspectos do processo de adaptação individual e grupal que podem subsidiar uma viagem ao espaço (Tafforin, 2009), os estressores psicológicos e comportamentais em missões de longa duração (Sandal et al., 2006), as normas comportamentais e as expectativas profissionais (Sarris e Kirby, 2007), a congruência de valores individuais e a cultura organizacional (Sarris e Kirby, 2005), além dos efeitos da estrutura organizacional sobre o comportamento e o desempenho de equipes polares e espaciais (Nolan e Dudley-Rowley, 2005). A maioria desses estudos usa dados secundários de fontes históricas ou de relatórios das agências nacionais envolvidas nas missões espaciais ou antárticas. Isto é, dificilmente se fundamentam em pesquisas diretas com dados colhidos in loco.

Apesar de já serem encontradas análises sobre aspectos organizacionais de algumas estações científicas na Antártica (Nolan e Dudley-Rowley, 2005; Sarris e Kirby, 2005), elas ainda são escassas e merecem ser ampliadas para incluir questões como: organização do trabalho, multiculturalidade dos grupos, comunicação organizacional, convivência intercultural, desempenho das equipes, sobreposição de estruturas organizacionais, cultura organizacional das estações científicas ou uma cultura partilhada por todos os pesquisadores, independente de nacionalidades. No caso brasileiro, podemos afirmar que ainda não foram desenvolvidas quaisquer pesquisas que levem em consideração aspectos sociológicos e organizacionais que nos permitam uma análise da organização do trabalho, dos aspectos psicossociais de indivíduos e grupos e, também, uma avaliação de desempenho de grupos ou dos processos de adaptação e interação entre os membros. Nesse sentido, a nossa pesquisa não pode se beneficiar de subsídios ou dados históricos que permitam comparações nem entre períodos nem com outras estações.

Entendemos que o fato de o trabalho ser realizado num local de difícil acesso, sob penosas condições geológicas e/ou climáticas, de imposição de isolamento e convivência confinada, põe em evidência a necessidade de se estudar o impacto gerado por essas condições, não apenas na qualidade do trabalho realizado (Villela, 2003), mas também no modo como seus executores o desenvolvem e vivem nesses ambientes e nos grupos (Palinkas e Browner, 1995). Para uma melhor compreensão da nossa pesquisa empírica, julgamos fundamental traçar o cenário em que nossos entrevistados atuam, acreditando que algumas das condições que eles enfrentam podem guardar semelhança ou afinidade com as de outros ambientes extremos. 


\section{0 contexto antártico e a complexidade do Proantar}

Tudo na Antártica é grandioso, superlativo e emocionante. A Antártica ocupa uma área de 14 milhões de $\mathrm{km}^{2}$, dos quais $95 \%$ são gelo, cuja espessura varia de 2.700 a 5.000 metros e representa aproximadamente $90 \%$ da água doce do planeta. Ventos correm até $360 \mathrm{~km} / \mathrm{hora}$. No inverno, a superfície pode ser ampliada em até 50 milhões de $\mathrm{km}^{2}$. Separada de outros continentes por mares tempestuosos e temperamentais, a Antártica continua a ser a região mais isolada do planeta, abrigando a mais diversificada fauna marinha biológica da Terra (Brito, 2009; EACF, 1997; Villela, 2003; Smith, 2001).

Os primeiros habitantes da Antártica foram os exploradores que a descobriram, ao contrário de outros continentes, onde foram encontrados nativos. Essa capacidade de começar algo do zero, de uma maneira completamente nova, permite aos indivíduos e grupos envolvidos revelarem sua identidade. Quebrar a terra gelada e procurar respostas para a vida é uma obra coletiva que expressa força e competência humanas (Alexander, 2000; Amundsen, 2001; Brito, 2009).

Há vários nomes importantes de exploradores antárticos, mas três deles são fundamentais em qualquer relato histórico: o do capitão inglês Robert Falcon Scott, o do capitão norueguês Roald Amundsen, numa expedição de 1910 a 1912, e o de Sir Ernest Shackleton, capitão escocês que no comando do navio Endurance esteve no continente de 1914 a 1917 (Alexander, 2000).

A Antártica não tem dono. $O$ primeiro acordo sobre o continente foi assinado por 12 nações em 1959. Atualmente, são 47 países signatários do Tratado, que foi renovado até 2048 . $O$ Tratado da Antártica prevê que apenas as nações que instalaram estações científicas ou bases podem decidir sobre o futuro do continente.

Terra da ciência e da paz, a Antártica desperta fantasias, desejos e utopias, o que mobiliza muita energia para o trabalho duro. A rotina diária é marcada pelo trabalho pesado, sob a liderança de militares e profissionais civis que escrevem uma história pessoal e profissional de sublimação, colaboração, determinação, dedicação e muito suor. A vida nos acampamentos e abrigos durante os invernos rigorosos desafia a imaginação de quem está no conforto do seu lar sedentário. A vida na Antártica mostra sinais de um primitivismo típico das sociedades tradicionais, e há muito tempo vem sendo estudada por antropólogos; nela, se percebe um claro sentimento igualitário e um grande respeito à natureza (Amundsen, 2001; Smith, 2001).

O Brasil aderiu ao Tratado da Antártica em 1975. Em 1982, nascia formalmente o Programa Antártico Brasileiro, sob o signo da inovação em gestão pública e assumindo uma gestão compartilhada entre os diversos órgãos das administrações direta e indireta. O Proantar é um complexo modelo de gestão interministerial que envolve o Ministério da Defesa, o Centro Nacional de Pesquisa e os ministérios do Meio Ambiente, das Minas e Energia, das Relações Exteriores e da Ciência e Tecnologia, sendo gerido pela Secretaria da Comissão Interministerial para os Recursos do Mar (Secirm). O Proantar é dividido em programas básicos relacionados às ciências da Terra, vida e ambiente.

Durante vários anos, o programa foi executado através de redes de pesquisa, nas quais os investigadores aprenderam a trabalhar juntos, a integrar seus interesses de pesquisa e 
a fazer melhor uso de recursos financeiros, além da logística necessária (Brito, 2009). Os pesquisadores eram os responsáveis por atribuir tarefas e vagas para os projetos, a fim de maximizar os recursos. Atualmente, o programa tem criado institutos para dirigir e integrar a investigação, devendo ser fundado em seu âmbito um Instituto Polar para centralizar todos os esforços.

Os cientistas brasileiros na Antártica dispõem de três tipos de acomodações, dependendo da natureza de seu projeto de pesquisa: uma estação científica, dois navios oceanográficos e dois abrigos/acampamentos. A EACF, inaugurada em 1984, tem atualmente capacidade para acomodar 50 pessoas num total de 2.250 metros quadrados, distribuídos entre a unidade central e os laboratórios (de biologia, geociências, ciências da atmosfera, meteorologia e o de química). Os dois navios oceanográficos, que também comportam laboratórios, são os principais pilares do Proantar, cuja função fundamental é dar suporte logístico à EACF e aos refúgios.

A gestão e a manutenção da EACF são exercidas pelo Arsenal de Marinha, representado por um grupo composto de três oficiais (chefe da estação, subchefe e médico/dentista) e de sete militares especializados em eletricidade, mecânica, eletrônica, comunicações e alpinismo. A seleção desses profissionais é atribuição do Arsenal de Marinha. O grupo pode permanecer na base durante todo o ano, e o chefe da estação é a autoridade máxima, responsável não apenas pela segurança de todos, mas também pela preservação dos materiais e pelo respeito às regras e rotinas. Depois de selecionados, trabalhadores civis e militares são submetidos não apenas a rigorosos exames médicos e odontológicos, mas também a um treinamento obrigatório de segurança e sobrevivência antártica.

Durante a temporada de verão (novembro-fevereiro), a estação recebe equipes de cientistas para os seus projetos. Também nesse período é retirado o lixo produzido durante o ano, são feitos os devidos reabastecimentos e trazido o material necessário para a manutenção e o conserto de instalações e equipamentos. Isso exige um planejamento detalhado, pois o que não for feito durante o verão ficará pendente até o verão seguinte, uma vez que navios ou aviões não chegam à Antártica no inverno.

Essa escala temporal é geralmente observada em outras estações científicas, mesmo nas maiores e com infraestrutura mais sofisticada, como a franco-italiana e a norte-americana. A estação Concórdia nasceu sob o signo da parceria entre França e Itália. Tem capacidade para acolher 16 pessoas no inverno e 32 cientistas no verão, dispondo ainda de um acampamento complementar para mais 40 pessoas no verão, além de laboratórios e hospital. Está a mais de 1.100 quilômetros da principal estação francesa, a Dumond D'Urville, e nela 13 pessoas fizeram sua primeira experiência de hibernação, em fevereiro de 2005 (Chaix, 2005; Tafforin, 2009). A principal estação norte-americana, a McMurdo, é a maior do continente, com um movimento de 1.100 pessoas durante o verão. Ela dispõe de aeroporto, caixas bancários (outras estações não usam dinheiro), placas de trânsito com limite de velocidade e linha de ônibus para a ligação com a base Scott, da Nova Zelândia, distante $3 \mathrm{~km}$. McMurdo utiliza trabalho civil voluntário para funções de apoio, logística e manutenção, disponibilizando vagas na internet e mantendo uma proporção de três trabalhadores por cientista durante o verão (Smith, 2001). 


\section{Pesquisa empírica: trabalhadores antárticos brasileiros}

Nossa pesquisa é um estudo descritivo, empírico, qualitativo, exploratório e interpretativo. É descritivo porque reproduz informações e dados oficiais divulgados em documentos e em sites de instituições envolvidas, como o Proantar e a EACF. É empírico na medida em que foi realizada pesquisa de campo, de natureza qualitativa, com profissionais que participam do Programa Antártico Brasileiro. Como nenhum outro estudo com foco organizacional foi ainda realizado, ele é exploratório porque investiga a natureza do objeto e apresenta características de uma determinada população. É interpretativo por buscar entender como os indivíduos criam e impõem ordem em seu mundo e como interpretam sua práxis como grupo específico (Bauer e Gaskell, 2004; Burrel e Morgan, 1979; Vergara, 2008; Enriquez, 1992; Morgan, 1983).

\subsection{Sobre os sujeitos de pesquisa e os procedimentos de coleta de dados}

Entrevistamos 13 participantes voluntários, dos quais 12 são pesquisadores civis e um é militar, que ocupou o cargo de subchefe da estação. Todos os participantes tinham idade acima de 32 anos, sendo oito homens e cinco mulheres. Quanto ao estado civil: casados $43 \%$ do total, solteiros eram $43 \%$ e 14\% eram divorciados. Em relação ao local de domicílio, 70\% moravam em São Paulo, 15\% no Rio Grande do Sul e 15\% no Paraná. Os respondentes estavam ligados às universidades de São Paulo (USP), Federal do Rio Grande do Sul (UFRGS), Federal do Paraná (UFPR), ao Instituto Nacional de Pesquisas Espaciais (Inpe) e à Capitania dos Portos de Santos. O grupo militar, composto por 10 homens, foi escolhido pelo Arsenal de Marinha a partir de critérios próprios. A formação do entrevistado militar é em ciências navais, com aperfeiçoamento em mergulho profundo.

As áreas de formação em nível de pós-graduação de nossos entrevistados são geofísica, geoquímica, biologia, bioquímica, física, oceanografia e glaciologia, e $67 \%$ deles fizeram o seu curso de doutorado e/ou pós-doutorado no exterior. Em relação a outros idiomas, foram citados: inglês, francês, alemão, italiano, hebraico e árabe. Quanto ao número de viagens de que tinham participado: $58 \%$ tinham feito até quatro vezes, $25 \%$ foram de cinco a nove vezes e $17 \%$ foram de 10 a 14 vezes. O tempo médio de permanência era de quatro meses na estação durante o verão e de três meses no navio oceonográfico, observando-se que o grupo militar pode permanecer mais tempo. Mudanças recentes dividem o verão antártico em equipes que podem permancer, em média, um mês ou mais, dependendo do projeto.

Os dados foram coletados através de extenso questionário, aplicados diretamente (47\%) e por meio eletrônico (53\%), estruturado em cinco partes, as quais são consideradas unidades de conteúdo e têm as seguintes características:

1. identificação;

2. formação acadêmica e profissional; 
3. participação em equipes, projetos ou expedições internacionais, coordenação, conflitos, dinâmica das equipes etc.;

4. vida na estação durante as participações: convivência civil e militar, treinamento, regras, espaços de trabalho e moradia, lazer, sentimento de solidão e situações críticas, cooperação, contatos com família e amigos, retorno a casa, sugestões para colegas inexperientes;

5. a EACF e vizinhança: dinâmica dos encontros com os vizinhos de outras estações - interação, cooperação e diferenças culturais.

\subsection{Resultados da pesquisa com os pesquisadores brasileiros}

O grupo estudado define as suas áreas de concentração e especialidades como: geofísica, geoquímica, glaciologia, oceanografia, biologia, biologia marinha, farmácia/bioquímica, oceanografia química e ciências navais. Com duração de dois a três anos, os projetos podem ser renovados. Uma parte é desenvolvida na Antártica e outra, na instituição de origem do pesquisador. Tratando-se de equipes mistas, não foi mencionado nenhum problema relacionado com a questão de gênero. Em algumas especialidades, como glaciologia ou meteorologia, é predominante o sexo masculino; em outras, como biologia, prevalece o sexo feminino.

Não é incomum equipes brasileiras participarem de expedições internacionais ou terem alguns estrangeiros participando de expedições brasileiras. Foram citadas participações, em diferentes momentos, de colegas argentinos, franceses, chilenos, russos, alemães, belgas, urugaios, neozelandezes e americanos (Chevrier, 2000; Freitas, 2008; Théry, 2002). Cada equipe precisa de diferentes tipos de apoio logístico do grupo-base, como os alpinistas e mergulhadores, além das informações cruciais do meteorologista.

O trabalho de coordenação do projeto é tido como muito importante. Segundo nossos entrevistados, as qualidades necessárias para o bom desempenho são: conhecimento científico; liderança científica e administrativa; competência nas relações interpessoais do grupo e experiência de campo; além de ser reconhecido como dedicado ao seu trabalho; tratar seres humanos com sabedoria e entusiasmo; ser atento e manter o espírito de equipe; ser flexível, mas firme; e capaz de lidar com imprevistos. A Antártica continua sendo uma terra inóspita, os perigos persistem, o trabalho desenvolvido lá exige organização, cuidados e equipamentos adequados. A tecnologia disponível hoje nos transportes e nas comunicações, nos equipamentos, roupas, medicamentos e alimentos facilita a vida dos cientistas, mas os papéis exercidos pela autoridade em matéria de segurança e de liderança na coordenação do trabalho continuam fundamentais (Boisot et al., 2011; Carrieri et al., 2010; Weick, 1995).

Sobre o espaço físico, não há passagem entre os espaços públicos e privados na Antártica, o que cria um paradoxo quotidiano: finitude dos espaços internos (estação, navios ou acampamentos) e vastidão do espaço exterior. Os rituais pessoais são partilhados pelas mesmas pessoas com quem se trabalha. Isto é, não há lugar para privacidade, pois até mesmo os 
locais de dormir são compartilhados com colegas (Nolan e Dudley-Rowley, 2005; Palinkas e Suedfeld, 2008; Sandal et al., 2006).

Apesar do confinamento, os entrevistados não manifestaram nenhuma reação negativa a esse aspecto, mencionando que isso é vivido com bastante naturalidade, especialmente os grupos que trabalham nas temporadas rápidas do verão. Todos lá são estrangeiros, sendo o quotidiano na Antártica indissociável da presença do outro em um espaço confinado. O que pode ser insignificante numa cidade, nesse universo torna-se intenso, por isso a enorme importância do respeito ao espaço do outro e de suas necessidades, o exercício da alteridade, a criatividade e o bom humor. O outro é constituinte do eu (De Certeau, 1990; Demorgon, 2004; Mutabazi e Pierre, 2008).

A respeito das diferenças culturais nas relações com os vizinhos na ilha Rei George (Argentina, Chile, Coreia do Sul, Polônia, Rússia e Uruguai), os entrevistados disseram que elas são importantes, não apenas por causa do trabalho, mas como estímulo pessoal e fonte de crescimento (Palinkas e Suedfeld, 2008). De acordo com eles, construir complementaridades interculturais exige disponibilidade para se adaptar a diferentes formas de trabalhar juntos e de resolver problemas, mas que, em vista do objetivo comum, as diferenças culturais despertam curiosidade, estimulam a imaginação, proporcionam aprendizagem e enriquecem as interações (Freitas, 2008; Mutabazi e Pierre, 2008; Théry, 2002). Não foram considerados relevantes problemas oriundos da comunicação em diferentes idiomas, pois todos falam, pelo menos, o idioma inglês.

Percebe-se que a interculturalidade é uma característica marcante não só nas interações com colegas estrangeiros, mas também entre os brasileiros, pois eles trabalham em diferentes instituições, são de diferentes etnias, vivem em cidades diferentes e têm diferentes experiências profissionais (Freitas, 2008; Mutabazi e Pierre, 2008). Quando um grupo diverso se integra, o resultado é considerado superior. Entretanto, a heterogeneidade pode ser também uma fonte de mal-entendidos e de elevação de conflitos, seja por vícios e vieses profissionais, por falha de comunicação ou por diferenças de personalidade. Para produzir melhores resultados, a interculturalidade deve ser valorizada como um desafio e merecedora de investimento pessoal para superar as dificuldades. Nesse sentido, todos os nossos entrevistados se declararam réus confessos, dispostos a conviver em grupos mais diversificados (Avela Neto, 2003; Boisot et al., 2011).

A experiência coletiva é construída por pesquisadores em vários níveis: a) local de trabalho: estação, navios, abrigos e acampamentos; b) equipe do projeto: na Antártica, na universidade/instituto; c) comunidade científica brasileira (Proantar); e d) comunidade científica internacional como um todo, o que torna sempre necessária a menção do nível de análise a que se está referindo quando é feita alguma observação.

A chegada à Antártica pressupõe a aceitação de certas regras, e nenhuma delas é mais rigorosa do que a relacionada à segurança (Brito, 2009; Sarris e Kirby, 2007). Em qualquer situação, a segurança é o ponto inegociável. Para outros assuntos, a negociação parece ser um traço dominante, tanto em termos pessoais quanto profissionais. Todo grupo coexiste criando regras para seu funcionamento, desenvolvendo maneiras práticas para lidar com a incerteza e 
com o sentido do que vivem e procuram. Uma vez que esse conhecimento e aprendizado são testados no tempo e fornecem respostas positivas para os problemas que pretendem resolver, então, essas respostas passam a ser vistas como o correto para essas situações. Com isso, um esquema de interpretação se define para uso futuro, se as condições permanecerem constantes (Freitas, 2007; Sarris e Kirby, 2005).

Na EACF existe uma rotina de organização, de gestão do tempo e do ambiente sob a responsabilidade das autoridades militares. Por outro lado, os cientistas têm autonomia para tratar dos assuntos relacionados à execução de seus projetos, exceto no que envolva a segurança. Isso significa que um cronograma será atrasado se o comandante julgar que as condições exteriores são arriscadas e não permitir a saída da estação. Como lazer, quando o tempo permite, os pesquisadores fazem caminhadas, praticam corrida ou esqui e jogam futebol. Vez ou outra, a equipe brasileira, ao organizar um churrasco ou uma festa convida vizinhos das bases mais próximas. Porém, é sempre um convite restrito, visto que precisa levar em conta uma possível mudança do tempo, que pode obrigar o convidado a se hospedar por tempo indeterminado, causando assim impacto no uso dos espaços e nos estoques de alimentos.

São claramente identificados dois grupos de trabalho diferentes na Antártica: um é representado pelos cientistas e o outro, por militares gestores da estação e dos navios. Cada grupo interpreta sua prática como específica, com valores distintos e sentido de missão a cumprir. São grupos com formação altamente especializada, profunda dedicação à tarefa e alto nível de disciplina, que se manifestam de formas diferenciadas. Para os militares, a hierarquia é pedra fundamental; para os cientistas, a autonomia é pedra fundamental. Percebemos em nossas entrevistas que essa diferença pode causar alguns atritos. Porém, no geral, militares e civis têm o entendimento de que o grupo-base está lá para garantir as condições de realização da pesquisa, embora os pesquisadores, em particular, também tenham o compromisso de fazer com que as coisas funcionem a contento e o convívio seja harmonioso.

Quando perguntados sobre possíveis punições à violação de regras, todos foram unânimes em responder que desconheciam alguma punição formal aplicada no sentido de uma remoção para o Brasil. Entretanto, não foi descartada a possibilidade de que o responsável por problemas tenha sua participação vetada em futuros trabalhos.

O grupo de pesquisadores brasileiros é composto por pessoas de diferentes origens, formações, vínculos institucionais e tipos de projeto em que trabalham. Elas vivem na Antártica conscientes da supremacia da natureza, dos limites de suas ações e da pequenez de cada um que enfrenta constantemente a luta pela sobrevivência e pela execução de suas tarefas. Nossos entrevistados revelaram que as diferenças ajudam a construir laços para desenvolver e fortalecer uma base comum e buscar sinergias. Isso revela um traço da cultura brasileira associado à valorização da novidade e à flexibilidade. Os investigadores disseram que, ao retonar às suas aldeias, cidades e universidades sedentárias, sentem-se desorientados, têm problemas com a luz, com o trânsito, com a agitada multidão urbana e com o uso de dinheiro, necessitando de alguns dias para se adaptarem. Confessaram ter saudades do silêncio e do infinito como paisagem. 


\section{Uma análise organizacional da Antártica}

Fazer uma análise organizacional da Antártica pressupõe entender o continente como um grupo de homens e organizações coordenando recursos intelectuais, financeiros, materiais, tecnológicos e normativos para atingir objetivos. A missão, tal como definida no Tratado e obedecida por todos os países signatários, exerce um papel essencial e atua como elemento integrador de cada estação e grupo, colocando-os sob as mesmas diretrizes gerais. Ou seja, mesmo que cada estação tenha objetivos próprios ligados às prioridades de pesquisa e políticas de seus governos, elas compartilham não apenas do contexto físico, mas das restrições impostas pelos acordos e leis internacionais que regem a matéria. Portanto, as estações instaladas podem ser vistas como partes descentralizadas de uma grande estrutura material, normativa, legal, financeira, tecnológica e científica desenvolvida no continente.

Fischer (1996) trabalhou o conceito de cidade como uma organização - bem como as múltiplas aplicações dessa estrutura conceitual — para analisar cidades como Salvador, Barcelona e Cidade do México, considerando a diversidade de organizações e a teia de relações que unem as pessoas, os artefatos e a natureza na cidade. Guardadas as devidas proporções e níveis de complexidade, esse conceito está implícito em nossa proposta de análise do continente antártico como uma organização. Neste estudo, o entendimento é de que o continente é constituído por diferentes modelos e níveis organizacionais, distintos sistemas de governo, diversificados recursos materiais, científicos, políticos, financeiros e regulatórios, como qualquer conglomerado organizacional complexo.

Nossa premissa básica é a de que a Antártica pode ser vista através de um conjunto de metáforas que permitem compreendê-la e analisá-la como fenômeno organizacional, pois se trata de uma construção de homens e grupos que representam organizações como governos, universidades e institutos de pesquisa, sendo, portanto, o resultado objetivado da ação humana deliberada e coordenada (Clegg et al., 1999; Enriquez, 1992; Morgan, 1996; Scheidhauer, 1994; Weick, 1995; Nirenberg, 1993; Villela, 2003).

As organizações são sistemas complexos, ambíguos e, por vezes, paradoxais que podem ser analisados a partir de várias perspectivas e métodos. Nós escolhemos o método analógico (Bauer e Gaskell, 2004; Enriquez, 1992; Morgan, 1996; Vergara, 2008), pelo qual as metáforas não são recursos de linguagem, mas uma maneira de pensar o mundo que determina a compreensão dos fenômenos e de aspectos organizacionais que coexistem e se complementam, mesmo quando se contradizem. Portanto, recorrer a metáforas nos permite explorar novas perspectivas, focando alguns pontos obscuros, ampliando-os e revelando novos ângulos dos problemas e das situações. Podemos dizer que as metáforas funcionam como um tipo ideal, uma vez que conduzem a um recorte para interpretar elementos tidos como privilegiados. No entanto, temos claro que nenhuma metáfora é suficiente para se analisar toda a complexidade de uma organização social ou entidade. Algumas das metáforas aqui usadas são clássicas e conhecidas na teoria das organizações (Bertalanffy, 1968; Enriquez, 1992; Morgan, 1996; Motta e Vasconcelos, 2002); outras são construções nossas inspiradas na semelhança dos fenômenos observados e em conceitos ou termos oriundos de nosso conhecimento no campo organizacional. 


\section{a. Antárctica como um organismo}

A análise da Antártica a partir dessa metáfora (Bertalanffy, 1968; Morgan, 1996; Motta e Vasconcelos, 2002) - que considera a teoria dos sistemas e o processo de influência entre os diversos subsistemas e o sistema geral - abre algumas perspectivas:

a) impactos recíprocos do ambiente físico continente-planeta. Isto é, a Antártica como testemunha das grandes mudanças ocorridas no planeta e os impactos que o próprio continente pode causar no mesmo;

b) relação entre os subsistemas naturais antárticos propriamente ditos (fauna, flora, clima, gelo, relevo);

c) influências causadas por fatores humanos e pelo trabalho no continente, como o uso de máquinas e equipamentos movidos a petróleo e gás;

d) relações entre os subsistemas representados pelas estações científicas instaladas, cuja construção e operação alteram profundamente o local; e

e) processo de aprendizagem e produção de conhecimentos resultantes da exploração da Antártica, contribuindo para uma maior compreensão do planeta e do próprio continente em retroalimentação.

Uma possível aplicação dessa metáfora no âmbito organizacional nos permite analisar as relações entre os programas e seus subsistemas, que envolvem governos, organizações militares, universidades, institutos de pesquisa, patrocinadores e grupos de voluntários. Considerando o Proantar como um sistema maior, a metáfora do organismo põe ênfase nas relações interorganizacionais já existentes e na abertura potencial para novos membros institucionais. Isso significa compreender como essa rede flexível cresce, se desenvolve ou se mantém a partir de um padrão de variação encontrado nessa complexa interação interorganizacional e nas definições de natureza científica, técnica e política já efetivadas ou a serem construídas. Ademais, a metáfora permite investigar os riscos que o sistema como um todo apresenta para a sua própria sobrevivência e crescimento. Quais são os limites do sistema atual? Que tipo de insumos seria necessário para tornar o sistema mais dinâmico, mais ágil e eficaz? O sistema tem gerado em seu próprio benefício todas as informações de que precisa para fazer melhorias? Como evitar o envelhecimento prematuro ou a esclerose do sistema atual ou de suas partes?

\section{b. Antártica como um conjunto de estruturas organizacionais}

Essa metáfora explicita os vários níveis que devem ser analisados, visto que eles dizem respeito a diferentes tarefas, laços de controle e sentidos de direção (Clegg et al., 1999). No nível internacional, temos as diretrizes delineadas no Tratado da Antártica, que definem a missão do continente e as obrigações dos países-membros. No nível nacional, temos as estruturas 
dos governos dos países-membros, criando suas estações, seus programas e suas políticas. O nível regional diz respeito às instituições acadêmicas diretamente envolvidas na execução e práticas do Projeto Antártico. As determinações no nível local referem-se à execução de projetos. As características da estrutura ad hoc são facilmente identificadas no trabalho científico: ênfase na especialização, estrutura organizacional flexível, trabalho por equipe de projetos, descentralização do poder, estrutura matricial e sistemas técnicos sofisticados em ambiente complexo e dinâmico (Boisot et al., 2011; Mintzberg, 2003).

Essa estrutura pode apresentar alguns problemas devido a seus laços frouxos, levando à confusão e ambiguidade entre os membros, dando margem ao risco de politização da estrutura, pois as equipes multidisciplinares podem apresentar níveis mais altos de conflito, visto que trabalham com poucas regras, diferenças internas e subordinação ao grupo. Essa estrutura só é eficaz para a realização de trabalhos extraordinários e não padronizados, pois têm um elevado custo de comunicação que deve envolver todos os níveis (Mintzberg, 2003; Motta e Vasconcelos, 2002).

A principal limitação da análise da Antártica como um conjunto de estruturas é o fato de que o objeto dispõe de apenas uma macroestrutura formal representada pelo Tratado. Há total autonomia dos países na definição de suas prioridades de pesquisa, o que resulta na potencial duplicação temática e no pouco planejamento dos investimentos totais feitos. A comunidade científica age como controladora da agenda de pesquisa, utilizando os canais de comunicação em congressos e simpósios. A principal fonte de poder dos membros dessa estrutura decorre do respeito e da reputação entre pares e das habilidades interpessoais dos líderes no que diz respeito à comunidade científica, enquanto a gestão quotidiana a cargo dos militares segue o modelo clássico de estrutura funcional, baseado na hierarquia e nas regras.

\section{c. Antártica como um sistema cultural, simbólico e imaginário}

Enriquez (1992) desenvolve um quadro conceitual que pressupõe que toda organização é ao mesmo tempo um sistema cultural, simbólico e imaginário.

Como sistema cultural, o autor se refere a uma estrutura de valores e normas, à construção de um modo de pensar e a uma forma de compreender o mundo que orienta o comportamento dos diversos membros da organização. Todo sistema cultural seleciona os valores básicos que determinam o que é importante e, ao mesmo tempo, os seus limites e tabus. O simbólico refere-se ao sistema de criação ou à instituição de mitos unificadores, aos heróis que tornam o sucesso humano e possível, aos rituais de celebração, às sagas que revigoram a memória coletiva do grupo e às histórias que valorizam os seus modelos. O sistema imaginário é colocado do lado do projeto a ser implementado, do ideal a ser construído, do futuro a ser atingido. Ele orienta a missão a ser realizada pelo grupo e a diferencia de todos os demais sistemas culturais, reforçando a interiorização de valores e o sentimento de pertencimento dos membros do grupo, despertando sua admiração pelos líderes e perpetuando a memória coletiva através da identificação, da idealização e do afeto (Enriquez, 1992; Motta e Freitas, 
2000; Freitas, 1999). Trata-se, portanto, de um sofisticado controle institucionalizado da subjetividade dos indivíduos.

Essa análise pode ser aplicada no caso do continente antártico, pois o sistema cultural vigente resulta do Tratado da Antártica, o qual estabelece os valores a serem compartilhados por todos os países que ali desejem se estabelecer. O sistema simbólico é representado por todos os modelos, exemplos, sagas de heróis e exploradores associados à história heroica da Antártica. O sistema imaginário define a missão, o projeto ao qual irá se aderir e o ideal a ser construído, pois a tarefa antártica — desde sua criação — só foi possível porque um dia alguém imaginou e acreditou que ela seria possível.

Poderíamos dizer que a principal limitação dessa metáfora está ligada à missão definida pelo fundador-chave da organização, ou seja, o Tratado da Antártica, pois, uma vez alterada essa missão, o sistema como um todo será completamente modificado, o que transformará não apenas a correlação de forças entre os países-membros, mas também os significados construídos. Portanto, ocorre uma ruptura potencial implícita, determinada pelo respeito às condições do Tratado. Nesse sentido, é possível que, além dos valores gerais ditados pelo Tratado e partilhados pelos pesquisadores antárticos, cada estação apresente especificidades de sua própria cultura organizacional que moldam o desempenho e definem a forma de integração de seus membros (Sarris e Kirby, 2005).

\section{d. Antártica como um sistema político}

Ambientes organizacionais não são neutros, nem os seus membros são uniformes em sua composição, objetivos, formas de pensar e de agir ou nos lugares que ocupam no conjunto. Interesses, conflitos e poder são inerentes a qualquer sistema político. O que diferencia um grupo de uma multidão é a existência de um objetivo comum e de um senso de direção para atingir essa meta. Entretanto, nem sempre esses resultam de decisões unânimes do grupo, visto que existem interesses conflitantes e uma busca de legitimidade para suas demandas.

A natureza dos conflitos organizacionais potenciais (Morgan, 1996; Motta e Vasconcelos, 2002; Pruitt, 1981) na Antártica e sua magnitude dependem do nível em que se expressam. Sugerimos algumas possibilidades:

a) o nível institucional implica a igualdade de participação entre membros e os acordos entre todas as partes;

b) no nível nacional, os potenciais conflitos tendem a ser mais práticos, uma vez que as instituições envolvidas são responsáveis por definir suas prioridades com base em planos governamentais e orçamentos;

c) os níveis regional e local são executantes das políticas e diretrizes, representados por universidades, institutos de pesquisa e estações científicas. A base de poder na atividade-fim é exercida predominantemente por meio do conhecimento, da experiência e da reputação entre pares. Nesse sentido, podem ocorrer conflitos potenciais derivados de eventual ultra- 
passagem das fronteiras de domínios de conhecimentos, bem como sobreposição de tarefas e territórios, soberania de estatutos profissionais dos membros dos diferentes grupos, disputas narcisistas de personalidades envolvidas, maior relevância de algumas áreas em detrimento de outras e níveis da autonomia das várias partes.

Há uma dinâmica entre esses diferentes níveis e são verificadas influências recíprocas entre as suas partes. Isso significa que uma alteração em qualquer nível provoca alterações nas outras partes, criando a necessidade de negociação de novas regras, direções, diferenças e interações (Motta e Vasconcelos, 2002; Palinkas e Suedfeld, 2008; Pruitt, 1981; Sarris e Kirby, 2007). Também não podemos esquecer que os processos de tomada de decisão em diferentes níveis podem levar a diferentes direções, com ou sem consulta e participação de todos os interessados, abrindo espaço para mais desacordo, mais defesa de interesses e mais conflitos a serem resolvidos. Mudanças organizacionais que transformam completamente o objeto podem levar a um estágio mais produtivo e vigoroso, mas também podem matar o próprio objeto. A limitação dessa metáfora é a possibilidade de todos os processos organizacionais serem vistos como jogos de poder, construção do império, agendas escondidas e disputas. A metáfora também desconsidera o peso político da interação e da competência das coordenações, inerentes a interações mais heterogêneas de múltiplos atores, ou mesmo o uso de mediadores.

\section{e. Antártica como um projeto grupal}

O pesquisador da Antártica é uma pessoa que só existe no coletivo, porque desde o início é necessária a sua inclusão em um grupo para que consiga explicitar suas pretensões científicas e obtenha a aprovação dos projetos a serem realizados in loco. Nenhum indivíduo tem acesso sozinho à Antártica. Ao contrário de outros lugares cujo acesso é difícil, mas possível, trata-se de um continente cheio de mistérios e perigos, em virtude das mudanças bruscas do clima e da geologia difícil, o que exige apurado planejamento, conhecimento e apoio logístico. Cada pesquisador deve ter seu projeto aprovado por um grupo institucional e atender a determinados critérios que definem categorias, linhas de pesquisa e objetivos. Em suas várias esferas e níveis, os grupos se identificam como membros temporários ou permanentes das comissões, conselhos e coordenações que decidem e implementam as decisões tomadas. Ao apresentarmos a metáfora do sistema cultural, simbólico e imaginário já pressupúnhamos a existência de um grupo, pois somente ele é capaz de criar um sistema de valores, uma representação de si como um grupo separado e um projeto a ser realizado (Enriquez, 1992; Freitas, 1999; 2007; Motta e Freitas, 2000).

Reconhecemos uma comunidade de pesquisadores da Antártica, que compartilha interesses, curiosidades, experiências, estudos, desafios e projetos a serem realizados. Essa comunidade pode ser vista como um sistema aberto, que consiste de vários grupos que atuam em diferentes esferas institucionais, ligadas a projetos de âmbitos e durações diferentes. Cada membro é, em certa medida, porta-voz e fiador de algo além de si mesmo e justifica sua ação 
(Enriquez, 1992). Observamos nesses grupos a forte dependência uns dos outros para garantir sua sobrevivência e para uma convivência provisória menos conflituosa (Anzieu, 1984; Freitas, 1999; Palinkas e Suedfeld, 2008; Sarris e Kirby, 2007; Nirenberg, 1993; Palinkas e Browner, 1995). O reconhecimento da ciência como um trabalho coletivo, fronteiras de desempenho, ausência de símbolos de status e uso de dinheiro, formação disciplinada e comprometimento com o trabalho, aceitação do outro como necessário, bem como a internalização da missão e valores, são fatores contingenciais que podem reduzir o risco de ruptura e colapso do grupo.

\section{f. Antártica como uma construção de nômades}

A história humana é um registro simultâneo e contínuo de alternância de ordem e mudança, movimento de destruição e criação, descobertas e invenções. Apesar da invenção das cidades e lares sedentários, a humanidade nunca ficou parada, sem contatos, viagens e notícias. Há milhões de anos, por muitas razões, os seres humanos se deslocam de um lugar para outro, buscam oportunidades e aventuras em mundos desconhecidos e cruzam mares violentos, enfrentam inimagináveis temperaturas quentes e frias, constroem monumentos e santuários em lugares improváveis e, mais recentemente, passaram mesmo a viver fora do planeta Terra.

Attali (2003) assume que o homem foi física, mental e culturalmente constituído através do nomadismo. O ponto de partida dessa grande aventura, há cerca de 5 milhões de anos, teria sido quando certo tipo de primata desceu de árvores para buscar alimentos. Durante essa busca, esse primata mudou: ele inventou ferramentas de pedra, ergueu-se sobre duas pernas, organizou-se em tribos, inventou deuses e sacrifícios, percorreu grandes distâncias e atravessou oceanos congelados. Também aprendeu a fazer intercâmbio e inventou o mercado, domesticou plantas e animais, descobriu o fogo e a roda, plantou e colheu grãos, aprendeu a trabalhar metais e cerâmicas, criou alfabetos e números, inventou línguas, expressou-se pela arte criada sob a forma de música, pintura e escultura, elaborou leis, assim como criou o livro, o barco e a Marinha, tendo ainda domesticado o tempo e o espaço. E aqui estamos nós!

A história da Antártica é uma história feita por nômadas (Attali, 2003; Maffesoli, 1997; Michel, 2005). Todos os indivíduos que dela fizeram e fazem parte são estrangeiros. A Antártica é um lugar temporário para viver; um lugar de temporada, fora do tempo, um não lugar. O fato de que existe um trabalho a ser feito não invalida seu estatuto como um lugar de passagem, porque ninguém fica permanentemente (Augé, 2008). Até hoje, as construções feitas no continente são de uso restrito aos grupos que lá trabalham, sem desperdícios; ou seja, os edifícios são modestos e minimalistas, todos os resíduos e lixo são removidos durante o verão, todo o consumo é simplificado e limitado ao essencial. Essa austeridade é condição de uma vida frugal que apenas uma existência transitória pode comportar e aceitar.

O trabalho na Antártica é sempre uma fase de um projeto maior que é desenvolvido nas universidades e institutos. Os cientistas precisam de uma infraestrutura mais complexa e sofisticada do que a disponível nas estações científicas, mesmo as mais bem equipadas. Apesar da miniaturização da tecnologia, do aumento da capacidade de armazenamento e da 
velocidade de viagem de dados, os pesquisadores precisam de seu espaço e sua vida sedentária. Eles precisam de suas conferências e simpósios para debate entre pares, precisam de suas salas de aula, seus alunos, seus livros, das normas e regras que estruturam e disciplinam o trabalho acadêmico. Essa metáfora lança luz sobre o tipo de potencial humano (Palinkas e Suedfeld, 2008; Sarris e Kirby, 2005, 2007) que vai melhor cumprir a missão na Antártica. Isto é, alguém com preparo psicológico para viver uma vida de passagem, que pode fazer o vaivém entre uma fase nômade e sedentária, que pode pagar o preço da ambiguidade e da ambivalência de uma vida disciplinada e aventureira, que pode lidar com a falta de regulação institucional, que é aberto para tarefas inesperadas, que pode controlar o próprio trabalho, que é capaz de mergulhar na vastidão e de enfrentar a falta de condições ideais de trabalho, bem como a falta de liberdade imposta pelo confinamento e as condições meteorológicas extremas. Esses aspectos ainda precisam ser mais pesquisados.

\section{g. Antártica como uma utopia}

A teoria das organizações traz referências de autores utópicos que buscaram alternativas para formas institucionais, costumes e tradições do seu tempo. Empreendimentos coletivistas e cooperativos foram propostos por Charles Fourier (1772-1837) na França, por Robert Owen (1771-1857) e por Louis Blanc (1811-82). O século XX nos colocou diante de muitos projetos utópicos que se pretenderam amplamente nacionais, e mesmo internacionais, e que escreveram uma parte importante e perigosa da história deste planeta.

O que pensar de um continente sobre o qual o homem decidiu não ser seu mestre e proprietário? Um lugar onde o dinheiro não circula, onde as diferenças oriundas do status não são percebidas, onde a consciência da sobrevivência é imperativa e onde a voz da natureza é soberana, remetendo-nos à cidade imaginária de More (1968). A Antártica não é um continente como os outros.

Ao contrário de outras utopias construídas para nunca serem alcançadas, a Antártica é um gerúndio em design e conteúdo; construção em aberto de uma comunidade, um se fazer e refazer contínuo, um descobrir e compartilhar. Não é uma terra de antepassados. Portanto, não há um passado humano distante que pretenda ser a fonte dos homens de hoje ou de nações. A Antártica está deslocada no tempo, a história é a história que está sendo feita. É uma área que não tem um centro reconhecido como uma referência comum (econômica, religiosa, política, cultural ou administrativa). Ao contrário das utopias fechadas, a Antártica é uma obra coletiva e aberta, que se realiza no espírito igualitário, na diversidade e na alteridade (Mutabazi e Pierre, 2008).

A natureza humana individual e coletiva precisa de sonhos para dar vazão às suas necessidades. Precisa de ideais, de modelos de identificação para orientar decisões, ações, leis, planos e construções. Apesar de vivermos num mundo que consagra o individualismo e a competição - ou que vê nesta o caminho mais eficaz para se produzir resultados - são sempre possíveis novas ideias, novas questões e novos projetos. A Antártica é um tipo de organização 
fundada na cooperação e na partilha; um modelo de gestão que só faz sentido se o interesse essencial for o de explorar e preservar o território para o bem comum.

\section{Conclusões}

Cremos que um "modelo de gestão" como o da Antártica pode contribuir para a aprendizagem e melhoria na gestão de organizações complexas, baseadas no conhecimento, na medida em que ele destaca vários aspectos:

a) o conjunto das estruturas que formam o sistema Antártico, com um elevado nível de autonomia, além dos laços políticos como resultado de negociações e processos de institucionalização a partir de uma lei maior, pode ser útil ao mundo organizacional com sistemas em redes e governança suprainstitucional, clusters ou de grupos conglomerados, na medida em que a jurisdição e os limites de fronteira de cada parte sejam bem definidos e nos quais os sistemas baseados em conhecimento tenham autonomia para serem operacionalizados;

b) um complexo multi-institucional, com definição clara de competências, responsabilidades, interesses e jurisdição de cada agente pode inspirar a adoção de modelos de cooperação mais estreita entre as organizações parceiras, joint-ventures e alianças institucionais, quando os objetivos são negociados, assumidos e controlados pela parte e pelo conjunto;

c) a concentração de pesquisa em rede, abrigando uma diversidade de formações técnicocientíficas de várias universidades e institutos de pesquisa, põe o foco na sinergia multidisciplinar e na maximização dos recursos financeiros em resultados a longo prazo. Verifica-se que a variedade de expertises e um elevado nível de autonomia no trabalho são características intrinsecas à natureza das organizações complexas e baseadas em conhecimento; portanto o consenso dos pares sobre as fronteiras do grupo é de fundamental importância;

d) as pessoas envolvidas em projetos na Antártica desenvolvem uma mentalidade que assume como pré-requisitos a interculturalidade, a cooperação e a ciência como um trabalho coletivo - compartilhando informações e projetos - , a abertura para novos parceiros, a gestão participativa do projeto, a gestão de conflitos, a aprendizagem coletiva e a importância do comportamento do grupo na consecução dos objetivos. No caso da Antártica, a necessidade do outro ou a presença do outro é elemento fundador da interação, a partir da própria noção de sobrevivência física do pesquisador. Portanto, é desnecessário um trabalho maior de persuasão sobre a convivência coletiva;

e) embora os investimentos feitos no projeto antártico brasileiro ao longo de sua existência sejam tidos como insuficientes, o programa tem demonstrado sua força e continuidade devido ao forte poder da identificação positiva dos pesquisadores e à adesão ao projeto coletivo, o qual conseguiu inspirar em cada participante a força da cooperação, da complementaridade, da diversidade, da alteridade e da interculturalidade. A força e a continuidade do programa também se devem ao reconhecimento de cada um como parte de algo maior, ao 
poder de sinergia nas complementaridades e ao compartilhamento de informações, recursos e conhecimentos, além de um quadro normativo comum.

Em 2009, Elinor Ostrom foi indicada para o Prêmio Nobel de Economia (com Williamson). Ela refuta a ideia de que a propriedade comum possa terminar em colapso econômico e na destruição do meio ambiente, mostrando que - uma vez cumpridos determinados princípios - a propriedade comum pode funcionar muito bem e ter um desempenho superior aos obtidos por propriedades individuais. Para nós, a Antártica e a Estação Científica Internacional são excelentes exemplos dessa teorização.

Os estudos organizacionais podem aprofundar as pesquisas sobre a organização e a execução do trabalho desenvolvido em ambientes extremos, particularmente aqueles onde é possível a presença do pesquisador-trabalhador, de forma a realizarem-se observações in loco, envolver-se com o clima da organização, vivenciar as facilidades e as dificuldades do processo de adaptação dos grupos ao ambiente e à própria tarefa, minimizando os vieses verificados quando se trabalha com dados que os próprios entrevistados já interpretaram. Essas pesquisas poderão construir novas teorizações sobre fatores importantes em processos de seleção e treinamento de pessoas que trabalham em locais isolados ou confinados e sobre variáveis do comportamento organizacional e psicodinâmica do trabalho. Também possibilitarão teorizações por melhorias das condições de trabalho e ergonomia, sobre aspectos psicossociológicos e culturais que podem permitir a análise de novos tipos de organização - notadamente, aquelas baseadas em conhecimentos complexos e instaladas em ambientes extremos — bem como uma comparação dos traços de diferentes culturas organizacionais.

\section{Referências}

ALEXANDER, Caroline. Endurance: a lendária expedição de Schakleton à Antártica. São Paulo: Cia. das Letras, 2000.

AMILS, Ricardo et al. Life in extreme environments. The Netherlands: Springer, 2007.

AMUNDSEN, Roald. Polo Sul: relato da expedição antártica norueguesa a bordo do Fram 1910/1912. São Paulo: Alegro, 2001.

ANZIEU, Didieu. Le groupe et l'inconscient: l'imaginaire grupal. 2. ed. Paris: Dunod, 1984.

ATTALI, Jacques. L'homme nomade. Paris: Fayard, 2003.

AUGÉ, Marc. Não lugares. 7. ed. Campinas: Papirus, 2008.

AVELA NETO, Nelson. A multidisciplinaridade nos grupos de pesquisadores brasileiros na Antártica: modelos de cooperação profissional. São Paulo, Eaesp/FGV, Relatório Pibic, NPP, 2003.

BARNETT, John S.; KRING, Jason P. Human performance in extreme environments. Human Factors and Ergonomics Society Annual Proceedings, General Sessions, p. 961-964, 2003. 
BAUER, Martin W.; GASKELL, George. Pesquisa qualitativa com texto, imagem e som. Petrópolis: Vozes, 2004.

BERTALANFFY, Ludwing von. General system's theory: foundations, development, applications. Nova York: Braziller, 1968.

BISHOP, Sheryl L. Evaluation teams in extreme environments: from issues to answers. Aviation, Space and Environmental Medicine, v. 75, n. 7, p. C14-C21, 2004.

BOISOT, Max et al. Collisions and collaboration: the organization of learning in the Atlas experiment at the LHC. Oxford: Oxford Press, 2011.

BRITO, Tânia (Org.). O Brasil e o meio ambiente antártico. Brasília: MEC, 2009. (MEC/Explorando o ensino, v. 10).

BURGIERMAN, Denis R. Piratas no fim do mundo. Superinteressante, São Paulo, v. 17, n. 188, p. $48-57,2003$.

BURREL, Gibson; MORGAN, Gareth. Sociological paradigms and organizational analysis. Londres: Heineman Educational Books, 1979.

CARRIERI, Alexandre P.; SARAIVA, Luís A. Simbolismo organizacional no Brasil. São Paulo: Atlas, 2007.

CARRIERI, Alexandre P. et al. Identidade nas organizações. Curitiba: Juruá, 2010.

CHAIX, Jean-François. Antarctique: le labo plus froid du monde. Geomagazine, n. 316, p. 126-138, 2005.

CHEVRIER, Sylvie. Le management des equipes interculturelles. Paris: PUF, 2000.

CLEGG, Stewart et al. Handbook de estudos organizacionais. São Paulo: Atlas, 1999.

DE CERTEAU, Michel. Linvention du quotidien. Paris: Folio, 1990.

DEMORGON, Jacques. Complexité des cultures et de l'interculturel. Paris: Anthropos, 2004.

EACF. Estação Antártica Comandante Ferraz, Proantar. Brasília: s.n., 1997.

ENRIQUEZ, Eugène. Lorganisation en analyse. Paris: PUF, 1992.

FARJOUN, Moshe; STARBUCK, William H. Organizing at and beyond the limits. Organization Studies, Londres, v. 28, n. 4, p. 541-566, 2007.

FISCHER, Tânia D. (Org.). Gestão contemporânea: cidades estratégicas e organizações locais. Rio de Janeiro: FGV, 1996.

FREITAS, Maria E. Cultura organizacional: identidade, sedução e carisma. Rio de Janeiro: FGV, 1999.

FREITAS, Maria E. Cultura organizacional: evolução e críticas. São Paulo: Cengage, 2007.

FREITAS, Maria E. O imperativo intercultural na vida e na gestão contemporânea. Salvador, Revista O\&S, v. 15, n. 45, p. 79-89, abr./jun. 2008. 
MAFFESOLI, Michel. Du nomadisme. Paris: Livre de Poches, 1997.

MARQUES, Fabrício. Corrida sobre o gelo. Revista Fapesp Pesquisa, edição 194, p. 32-37, abr. 2012.

MICHEL, Franck. Autonomadie: essai sur le nomadisme et l'autonomie. Paris: Homnisphères, 2005.

MINTZBERG, Henry. Criando organizações eficazes: estruturas em cinco configurações. São Paulo: Atlas, 2003.

MORE, Thomas. Utopia. Rio de Janeiro: Edições de Ouro, 1968.

MORGAN, Gareth. Imagens da organização. São Paulo: Atlas, 1996.

MORGAN, G. (Ed.). Beyond method: strategies for social research. Londres: Sage, 1983.

MOTTA, Fernando C.P.; FREITAS, Maria E. (Org.). Vida psíquica e organização. Rio de Janeiro: FGV, 2000.

MOTTA, Fernando C.P.; VASCONCELOS, Isabella F.G. Teoria da administração. São Paulo: Atlas, 2002.

MUTABAZI, Evald; PIERRE, Philipe. Pour un management interculturel. Paris: L'Harmattan, 2008.

NIRENBERG, John. The living organization: transforming teams into workplace communities. Homewood: Business One Irwin; San Diego: Pfeiffer \& Co., 1993.

NOLAN, Patrick D.; DUDLEY-ROWLEY, Marilyn. Effects of organizational structure on the behavior and performance of polar and space work teams. Colúmbia: University of South Carolina, 2005.

PALINKAS, Lawrence A. et al. Incidence of psychiatric disorders after extended residence in Antarctica. International Journal of Circumpolar Healthy, v. 63, p. 157-168, 2004.

PALINKAS, Lawrence A.; BROWNER, Deirdre. Effects of prolonged isolation in extreme environments on stress, coping and depression. Journal of Apllied Social Psychology, n. 25, p. 557-576, 1995.

PALINKAS, Lawrence A.; SUEDFELD, Peter. Psychological effects of polar expeditions. The Lancet, v. 371, issue 9607, p. 153-163, 2008.

PRUITT, Dale G. Negotiation behavior. Nova York: Academic Press, 1981.

RODAHL, Kaare. Occupational healthy conditions in extreme environments. Annals of Occupational Hygiene, v. 7, p. 241-252, 2003.

SANDAL, Gro M. et al. Human challenges in polar and space environments. Review in Environmental Science and Biotechnology, v. 5, n. 2-3, p. 281-296, 2006.

SARRIS, Aspa; KIRBY, Neil. Antarctica: a study of person-culture fit. Australian Journal of Psychology, v. 57, n. 3, p. 161-169, 2005.

SARRIS, Aspa; KIRBY, Neil. Behavioral norms and expectations on Antarctic stations. Environment and Behavior, v. 39, n. 5, p. 706-723, 2007. 
SCHEIDHAUER, Marcel. Le symbolism chez Freud. Paris: Anthropos-Economica, 1994.

SMITH, Roff. Planeta branco. National Geographic Brasil, ano 2, n. 20, p. 108-140, 2001.

STARBUCK, William H.; FARJOUN, Morse (Ed.). Organization at the limit: lessons from the Columbia disaster. Oxford: Blackwell, 2005.

TAFFORIN, Carole. Life at the Franco-Italian Concordia Station in Antarctica for a voyage to Mars. Antrocom, v. 5, n. 1, p. 67-72, 2009.

THÉRY, Bruno. Manager dans la diversité culturelle. Paris: Editions d'Organisation, 2002.

VERGARA, Sylvia. Métodos de pesquisa em administração. São Paulo: Atlas, 2008.

VILLELA, Rubens. A lenta transfiguração polar. Scientific American-Brasil, n. 8, p. 38-43, 2003.

WEICK, Karl. Organizational culture as a source of high reliability. California Management Review, v. XXIX, n. 2, p. 112-127, Winter 1987.

WEICK, Karl. Sensemaking in organizations. NovaYork: Sage, 1995.

Maria Ester de Freitas é professora titular do Departamento de Administração Geral e Recursos Humanos da Escola de Administração de Empresas de São Paulo, da Fundação Getulio Vargas (FGV/Eaesp). E-mail: ester.freitas@fgv.br. 